\title{
Diversity and Inclusion in Health Workforce. Time for the Pygmalion Effect?
}

\author{
Stavroula (Valia) Kalaitzi* \\ ${ }^{1}$ Department of International Health, Faculty of Health, Medicine and Life Sciences, Maastricht University, Netherlands \\ ${ }^{2}$ Department of Global Health, Richard M. Fairbanks School of Public Health, Indiana University, USA
}

*Corresponding author: Stavroula (Valia) Kalaitzi, Department of International Health, Faculty of Health, Medicine and Life Sciences, Maastricht University, Netherlands; Department of Global Health, Richard M. Fairbanks School of Public Health, Indiana University, USA

\section{ARTICLE INFO}

Received: 幽 September 09, 2020

Published:

\section{ABSTRACT}

Citation: Kalaitzi, S. Diversity and Inclusion in Health Workforce. Time for the Pygmalion Effect?. Biomed J Sci \& Tech Res 30(4)-2020. BJSTR. MS.ID.004972.

\section{Short Communication}

The European healthcare sector is undergoing fundamental shifts towards becoming, amongst others, more diverse and inclusive in its workforce. Recently, diversity and inclusion challenges in health workforce gained impetus on the grounds of dramatically changed demographics, but mainly from the need to ensure that the best talents from all backgrounds contribute to the improvement of health and the performance of healthcare organizations. The current pandemic showed the scale of really profound and disturbing inadequacies in healthcare and public health arenas. It highlighted that working together is a condition sine qua non to achieve better and faster outcomes in serving the public health by protecting the human health and being beneficial to health systems. Equally important, it furthered the need to make a choice between tinkering at the edges or taking effective measures to develop and implement EDI policies and practices across healthcare organizations and reap the full potential of an inclusive and diversified health workforce.

At EU level laudable efforts have been made. For example, the Diversity and Inclusion Charter adopted by the EC [1] may be considered a valued token of the EC's interest to foster proactively a culture in which all employees are equally treasured, respected and provided with equal opportunities. Yet, it may be rather considered a pledge, a commitment aimed at encouraging organizations, either public institutions or private companies, to implement and develop relevant policies in the workplace and develop a culture of equality, diversity and inclusion (EDI) for the workforce which, in turn, will influence the much sought-after social cohesion.

Organizations are dynamic entities with a certain momentum running according to embedded organizational culture and climate [2]. Although potentially overlapping, these two entities are fundamental building blocks for understanding the social processes associated with individual and group behaviors within organizational context and, therefore, are viewed as key drivers to organizational change efforts $[3,4]$. On a sad note, literature reports extensively an unfriendly and non-supportive organizational culture in terms of EDI challenges. What is even more alarming is that an internal resistance driven by deeply rooted stereotypes along with cross-cutting issues (e.g. ethnicity, race, sexual orientation, intergenerational bias, etc.) is embedded firmly in organizational policies and practices resulting in a significant cost of talent and intellectual capital for both organizations and society [5,6]. Arguably, the change agents, namely the leaders, at all levels of leadership, and decision makers, have an impact both on organizational policies and on the patterns of behaviors.Yet, they may be poorly informed about the nature and the impact of embedded barriers to EDI challenges as well as about the best strategies and toolkits to address these challenges [6]. This knowledge gap results in underestimating the importance of the problem and, at best, to undertake frivolous initiatives and superficial measures. 
As a result, fuzzy, ambiguous perceptions on the range of EDI challenges within organizations may give rise to misleading estimations, diverging calibration of the challenges and erroneous actions and omissions. Worse still, scratching the tip of the iceberg could very easily lead to suboptimal taping into the available talent pool and, then, to reduce the capacity for improved organizational performance and to bring about substantial change at organizational and, at a broader note, at social level. Clearly, there is a pressing need for having a plain and factual picture of the actual reality in relation to EDI challenges in work settings. This cannot be achieved without disaggregated data. And, to paraphrase a Spanish poet, there is no such thing as a favorable wind for a sailor who has not yet set his course. Hence, real-time, grassroot, disaggregated data on barriers towards achieving EDI in work settings is needed to offer in the first place a valuable, reality check of the actual scope of the problem and, secondly, to generate accurate, updated mapping of the problem. Tools delivering valuable disaggregated data can contribute to digging up accurate information which is hidden behind firmly rooted stereotypes, biases, micro-aggressions and power relationships and develop regularly updated, digital databases.

Those databases, if used correctly and wisely, have the capacity to navigate and strengthen the organizational policies and practices, to create a culture of inclusiveness and diversity and to achieve measurable and benchmarked progress. But that will not suffice. We also need to develop Pygmalions ${ }^{1}$ at all levels of leadership, and decision makers who will catalyze positive performance by demonstrating and fostering higher, positive expectations. The Pygmalion effect involves leveraging followers' full capabilities and avoiding the obstacles created by low expectations within several contexts, including the organizational setting [7-9]. The followers grow to the level their leaders believe them [10, 11]. However, the effect drops off if the chance of success is estimated being less than 50\%; namely, if an endeavor seems either certain or completely uncertain, the Pygmalion effect does not hold [12]. In that perspective, the disaggregated, real-time data may facilitate the Pygmalion effect at all levels of leadership offering a reality compass and underpin informed decisions.

On the other hand, policy actors and decision makers make the rhetoric that they follow EDI policies and practices and apply available toolkits. Yet, learning and change is inherently a social process that cannot be separated from the context in which takes place [13]. On that note, the internal organizational capabilities, such as minimizing internal resistance or EDI related criticism, may be linked to the dedicated and informed change agents, namely to leaders and decision makers $[14,15]$.

The dialectics on EDI challenges within the context of organizational change may be enriched considering that the attainment of durable and sustainable change is a journey, not a destination, which is guided by shared driving principles and any progress made must be measured at predetermined milestones and evaluated against priorities and targets [6]. This knowledge must become a core organizational competency applied at all levels of leadership and, thus, to acknowledge in practice that the full potential of an organization's human capital is an essential driver of both organizational and social change. Taking stock on the lessons learnt from current pandemic in relation to sorely tested health workforce, a compelling case exists for ensuring that diversity and inclusion challenges is a key strategic priority. The Pygmalion effect may contribute towards developing consensus leadership, namely towards developing leaders fostering inclusion, engaging and empowering actively the diversified teams, be efficient and resilient.

\section{References}

1. European Commission (2017) Communication of the Commission. A better workplace for all: from equal opportunities towards diversity and inclusion.

2. Denison DR (1996) What is the difference between organizational culture and organizational climate? A native's point of view on a decade of paradigm wars. Academy of management review 21(3): 619-654.

3. Schneider B, Ehrhart MG, Macey WA (2011) Perspectives on organizational climate and culture. In S. Zedeck (Ed.), Handbook of industrial and organizational psychology 1: 373-414.

4. Ostroff C, Kinicki AJ, Muhammad RS (2012) Organizational culture and climate. Handbook of Psychology, Second (Edn.), 12.

5. Kalina P (2018) Challenges to Diversity and Inclusion in Health Care. Human Resource Management Research 8(3): 45-48.

6. Coe IR, Wiley R, Bekker LG (2019) Organisational best practices towards gender equality in science and medicine. The Lancet 393(10171): 587593.

7. Rosenthal R, Jacobsen L (1968) Pygmalion in the classroom: teacher expectation and pupils' intellectual development. New York: Holt, Rinehart and Winston.

8. Rao M, Sharma S (2016) Pygmalion In Management. IOSRJournal Of Business And Management, p. 15-23.

9. Eden D (1984) Self-fulfilling prophecy as a management tool: Harnessing Pygmalion. Academy of management Review 9(1): 64-73.

10. Livingston JS (2003) Pygmalion in Management. Harvard Business Review. Organizational Structure.

11. Livingston JS (2003) Pygmalion in management. Harvard Business Review Press.

12. Atkinson JW (1957) Motivational Determinants of Risk-Taking Behavior. Psychological Review 1(6): 359-372.

13. Wenger E (2010) Communities of practice and social learning systems: the career of a concept. Social learning systems and communities of practice, pp. 179-198.

14. Sharma A (2016) Managing diversity and equality in the workplace. Cogent Business \& Management 3(1): 1212682.

15. Köllen T (2015) Diversity management in the European health care sector: Trends, challenges, and opportunities. In Challenges and opportunities in health care management. (p. 27-45). Springer, Cham.

${ }^{1}$ Pygmalion is a proper noun, not used in plural. In this entry, the plural (Pygmalions) is used metaphorically to highlight the need for the multiplier effect of the phenomenon. 


\section{ISSN: 2574-1241}

DOI: $10.26717 /$ BJSTR.2020.30.004972

Valia Kalaitzi. Biomed J Sci \& Tech Res

(c) (P) This work is licensed under Creative

Commons Attribution 4.0 License

Submission Link: https://biomedres.us/submit-manuscript.php

$\begin{array}{ll}\text { BIOMEDICAL } & \text { Assets of Publishing with us } \\ \text { RESEARCHES } & \text { - Global archiving of articles } \\ \text { - Immediate, unrestricted online access }\end{array}$

